\title{
THE GLORY OF WINNING AND THE SHAME OF DEFEAT - THE SEX IS WAR METAPHOR AS A CREATIVE RESERVOIR AND A TOOL FOR ESTABLISHING MASCULINIZATION, POWER, AND DOMINANCE
}

\begin{abstract}
This article investigates the relationship between language and ideology and provides an account of the representation of sex as physical contact in contemporary American men's magazines, as well as the specific role that metaphors play in perpetuating the view that men are constructed as the aggressors and women as the victimized and attacked. The method applied to retrieve the data is manual searching. The analysis is carried out in the spirit of Cognitive Linguistics, with particular emphasis on the notion of Lakoff and Johnson's conceptual metaphor framework. It is based on the assumption that in many cases, the overall view of sex seems to be one of hostility, violence, and dominance, where the SEX IS WAR (but also SEX IS PUNISHMENT) metaphor functions as a device of masculinization since war is still typically perceived as a male activity, which, in turn, may lead to certain detrimental psychological consequences.
\end{abstract}

Keywords: Metaphor, ideology, war, sex, violence, media.

\section{INTRODUCTION}

It is no accident that sex constitutes one of the most basic and perhaps the most significant aspect of human nature. Its importance can be inferred from Maslow's theory on the hierarchy of individuals' basic needs (see Maslow, 1943). What is worth mentioning here, however, is that there are at least three different meanings of the notion of sex. The first one is strongly associated with the division of people into female and male genders on the basis of their reproductive functions. The second most common understanding of the term is connected with erotic preference (see Cameron, Kulick, 2003). Nonetheless, this article will be based on the third essential connotation of sex which the Oxford English Dictionary defines as "physical contact between individuals involving sexual stimulation; sexual activity or behaviour" (OED). Obviously (see Morton, 2003), the human race needs sex to survive and to ensure the multiplication of the species, although in modern times sexual activities are rather associated with hedonistic pleasures. What is more, western culture seems to be obsessed with sex, and one can easily assume that various types of

\footnotetext{
${ }^{1}$ Karolina Kurowska, M.A., the Department of English Studies, University of Rzeszów, al. mjr. W. Kopisto 2 B, 35-315 Rzeszów; e-mail: karolinakurowska@onet.pl. ORCID: 0000-0002-4529$-444 X$.
} 
media are saturated with sexual content (see del-Teso-Craviotto, 2006). Hence, with a view to bridging the research gap on the conceptualisation of sex-related aspects in men's magazines, this article will focus on the overwhelmingly ideological sexual metaphors SEX IS WAR and SEX IS PUNISHMENT (see section 4).

\section{AIMS}

By collecting and analysing terms for sexually-related actions, the main aim of this paper is to provide new insights into the relationship between linguistic expressions and cognitive conceptualisations of sexuality among readers of men's magazines, such as "Men's Health", "Playboy" and "Penthouse"2. The study is supported by numerous examples of figurative expressions from the aforementioned magazines (57 issues: $20-$ "Men's Health", 16 - "Playboy", 21 - "Penthouse", published from January 2016 to December 2017) that are carefully selected, classified and analysed on the basis of their belonging to the source domain in question. The method applied to retrieve the data is manual searching. The author has cautiously read throughout the pages searching for linguistic metaphors that contain SEX as a target domain ${ }^{3}$. What is more, sex-related metaphorical expressions are viewed here from the perspective of linguistic discrimination against women. The findings have shown that sex can generally be conceptualised as WAR, BATTLE and PUNISHMENT. What is more, several conceptual metaphors have been identified, such as SEX IS WAR, SEX IS PUNISHMENT, PENIS IS A WEAPON and KISSING IS WRESTLING.

Section 3 below starts with a review of the notion of conceptual metaphor and gives insights into its significance in human understanding. Section 4 examines in some detail the well-studied source domain of WAR in order to shed some light on the fact that much of what we do while having sex is shaped by concepts related to war. In section 5 , the author offers the most essential links between language and ideology, and discusses possible social implications and consequences of referring to the domain of WAR. In the final section, some conclusions are proposed together with indicating some potential outcomes, emphasising that the sex-related metaphors are cognitive devices according to which we live in our cultural sphere and that they shape our actions during various disputes.

Lastly, focusing on the application of sex metaphors in American magazines for men, this paper aims at identifying the most frequent sex-related metaphors used, investigating the significant relationship of erotic metaphors with the perception of women in western cultures, as well as how such metaphorical conceptualisations influence the targeted readers' beliefs and behaviour. In what follows, first, the theoretical background will be introduced.

\footnotetext{
2 In fact, although "Men's Health" is a good example of the magazine that this phrase implies, unfortunately, only a small portion of excerpts is taken from it and all the others are from pornographic magazines. The discussion refers to the representatives of the media, yet print pornography may be considered by some as not 'popular', conventional and mainstream. Indeed, in the nearest future, the study needs to take into account more magazine issues in order to identify more instances of the domain in question.

${ }^{3}$ It is difficult to provide the approximate total number of examples with metaphors that have been analysed. Moreover, instances of other types of sex-related metaphor have been encountered during data collection, such as SEX IS BASEBALL, SEX IS EATING, SEX IS BUSINESS, just to name a few.
} 


\section{METAPHORS: THEORETICAL PREREQUISITES}

In seeking to understand the significance of metaphor, one needs to start with the fact that in 1980, George Lakoff and Mark Johnson published the first edition of their seminal book Metaphors We Live By, in which they placed metaphor at the centre of interpersonal communication. According to cognitive linguists, metaphors possess special functions that facilitate human cognition ${ }^{4}$. In fact, metaphor treated as a conceptual phenomenon, which is expressed primarily in the way of thinking and acting, and not only in language, became a key term for all cognitive theory. Lakoff (1987) sees the sense of metaphor in understanding and experiencing one thing in terms of another, which consequently leads to the conclusion that the human conceptual system is, to a large extent, a system of interrelated analogies.

What is more, metaphor allows humans to perform a set of cross-domain mappings between two conceptual domains (a target domain - less known and usually more abstract, and a source domain - more physical and tangible), and hence, they reflect our conceptual structure $^{5}$. The simplest explanation is that they appear in speech because the human mind is metaphorical, so studying what we say can help us determine the way we think (see Kövecses, 2015; Kövecses, 2020). In addition, Lakoff and Johnson (1980) claim that "the most fundamental values in a culture will be coherent with the metaphorical structure of the most fundamental concepts in the culture". Therefore, the choice of metaphors is not coincidental. From a considerable number of conventional metaphors we tend to choose very specific ones, because they suit our views and our way of life best.

Since metaphors constitute an extremely fascinating phenomenon, research on figurative expressions is being conducted on a large scale and on multiple dissimilar dimensions. As one has learned, metaphor is not only a feature of language, and it is not only a feature of language and thought, either. Kövecses (2010) notices that "metaphor is a widely distributed phenomenon that encompasses all our cultural reality - including material culture and physical events". It shapes not just our communication, but also the way we think and operate. What is more, making sense of the surrounding world cannot take place without metaphor. Dobrovol'skij and Piirainen (2005) add: "[the] metaphor is therefore not just a means of naming, but an instrument of conceptualising the world. It also stands out as the principal device in cultural constructions."

\section{ANALYSIS}

What will become evident in what follows is that it is impossible to overlook the close bond between sex and war, since war terms are commonly used by ordinary people in everyday situations. Contemporary English language is loaded with hundreds of military terms which are repeatedly applied to non-military circumstances in everyday speech or writing, which has become a customary process, since both women and men are likely to draw upon phenomena in one area of life to understand experiences in another. Therefore,

\footnotetext{
${ }^{4}$ One needs to remember that the area of abstract thinking includes not only theoretical scientific constructs and metaphysical ideas, but also everyday concepts such as love or desire. It depends on language users which language realisations the metaphor will have; the user, thus, has the choice of conventional metaphorical phrases, but can also create an infinite number of new metaphors.

5 See, for instance: (Gibbs, 1994; Kövecses, 1986; Kövecses, 2005; Kövecses, 2008; Kövecses, 2010; Kövecses, 2020; Lakoff, Johnson, 1980).
} 
a brief theoretical overview of this domain in relation to sex will be helpful in further analysis.

\subsection{The Domain of $\mathrm{WAR}^{6}$}

To start with, the persistent and pervasive traditions and norms regarding gender roles give the impression that only men can be sexually active, while the role of women is to be merely the passive objects of masculine desire. Such a view is expressed by many researchers. Among others, Baider and Gesuato (2003) point out: "[t]he male is an agent engaged in an active act, while the female is a patient, recipient, experiencer or marginal, submissive agent." Taking another, more blunt, example, the feminist MacKinnon (1982) states: "[m]an fucks woman. Subject, verb, object". Unfortunately, even in modern times, such a perception of reality is not uncommon and has enormous negative consequences for women ${ }^{7}$. It evidently makes them vulnerable to sexual abuse and exploitation, and restricts their freedom since they start to be treated as objects rather than equal human subjects (Cameron, Kulick, 2003).

Turning to the metaphors for sex, it is remarkable how many of them employ violence as their source domain. Many of those figurative expressions are relatively recent in origin; however, as Goatly observes (2007), "the association can be traced back at least as far as classical times, where phallus meant 'sword', vagina meant 'sheath or scabbard' ". Duda (2014) provides similar examples which fit into the category of the metaphor SEX IS WAR, namely: sword, weapon and pole in the sense 'penis' and wound, cut, scar in the sense 'vagina'." Interestingly, examining the abovementioned examples one can safely conclude that men are again constructed as the aggressors, while women as the victimised and attacked ${ }^{8}$. The next section, thus, tries to contextualise which metaphors are used to talk about sex-related issues and how they influence the perception of women's and men's roles in the world.

\subsection{Sexual Intercourse}

In my opinion, the first claim that might be put forward is that sex itself is not an indisputably positive force that brings only intense physical pleasure and emotional fulfilment and satisfaction. Very often it can equally be a source of misery and unspeakable cruelty. In this connection, it is worth observing that there are many sex-related metaphors that utilise WAR domain as their foundation in the creation of figurative expressions. Because of such violent and ferocious associations they enhance the status of men as rough and impetuous, while at the same time they degrade womanhood to something weak and tender. Although one may say that they are only stereotypes, they certainly appeal to some elements of the lovers' psychology who unconsciously try to live up to social expectations.

\footnotetext{
${ }^{6}$ With the understanding of the figurative meanings connoted in the metaphors used on the pages of magazines aimed at adults, some readers may find some of the sex metaphors rather indecent or obscene, and therefore offensive.

${ }^{7}$ Sex and violence are linked in the human mind via metaphors that describe sexual desire in terms of physical force and war. Beside the fact that this kind of perception penalises women, Lakoff (1987) suggests that the way people conceptualise lust and anger, together with various folk theories of sexuality, may also constitute a contributing factor to the high rate of rapes in some societies.

${ }^{8}$ Beside the metaphor SEX IS WAR, Duda (2008) provides another SEX IS HUNTING, in which males are depicted as hunters and therefore attackers.
} 
Taking into consideration the nature and content of various men's magazines, it seems almost impossible to overlook the whole array of war and violence associations with regard to sexual activities. Principally, the domains of WAR and SEX noticeably overlap and there are a great number of metaphorical mappings between them. To illustrate the truth of this, it is worth analysing certain examples:

How to Sleep with Her: Bedroom strategies for better z's. "Men's Health" $1-2 / 2017$.

It was a battle of wills, both of us trying to hold out so the other would come first. "Penthouse" 2/2016.

Stoya's Guide to Expanding Your Sexual Frontiers. "Playboy” 7-8/2017.

A deep dive into America's final sexual frontier: the ass. "Penthouse" 7-8/2017.

All the aforementioned contexts represent the SEX IS WAR metaphor and they share some common features. The two people involved in sexual intercourse are seen as opposing fighters or even sworn enemies. However, the essence of the metaphor cannot be limited to the seduction stage. People seem to be involved in a love act as opponents; they attack their positions and defend them; gain and lose ground; as well as plan and use love strategies. Among other things, war also requires an enemy.

The metaphorical correspondences that appear between the domains of SEX and WAR can be presented graphically as follows:

Source: WAR

the conqueror

the conquered

the battle

surrender

battle strategy

\section{Target: SEX}

the man

the woman

the attempt to have sex

allow to have sex

bedroom strategy

On the one side, there is a man who dominates sexually and is considered to be a conqueror in the war. On the other side, there is a woman who is supposed to obey and submit to everything. Such portrayal is well depicted in the sentences below:

I think dominance and submission, which should probably be called surrender, is all a vast human construct on a basic primordial strategy in which the woman surrenders completely and the man totally dominates to impress her. "Men's Health" 3/2017.

All my body surrenders to thy tireless lips. "Penthouse" 2/2016.

The examples illustrate and emphasise the idea, which is deeply rooted and well established in many traditions and beliefs, that males should take the leading role during sexual intercourse, while women should unquestionably capitulate. The knowledge we have about war also allows us to provide other metaphorical entailments. Firstly, to seduce a sexual partner is to overcome a competitor and secondly, surrendering is allowing desire to take control. The WAR metaphor stresses and focuses predominantly on the issue of 
control. Additionally, contemporary models of masculinity have an enormous influence on the conceptualisation of men as violent partners in a sexual act. Masculinity is perceived as an aggressive and violent feature, simply because men are defined by their masculinity (they must act violently to be seen as masculine). It should have become clear from the examples that men are encouraged to demonstrate violence through sex in order to emphasise and assert their manhood. This situates men as attackers during sexual intercourse. One may also argue that the examples below, despite the war reference, are less about war and more about and the notion of punishment:

Raven turned the vibrator back up, and I started to thrust into Lily in powerful, punishing strokes. It was a foreign motion at first, but I quickly found a rhythm and got caught up in the moment. As I watched her come again and again while I hammered into her, I knew I would never forget my first time. "Penthouse" $10 / 2017$.

Kylie held on to the hood of the car while I gave her pussy the punishing it deserved, slapping her ass from time to time while she squealed and squirmed on my cock. "Penthouse" 1/2016.

Again, the conceptual mappings provide a participant structure which unquestionably evokes a relationship where one of the participants - the punishing one (a man) is performing the action, while the other participant - the person being punished (a woman) is receiving the action. Yet again, a man fulfils the role of an attacker, and a woman takes the role of an attacked. The metaphor SEX IS PUNISHMENT seems to be an excellent example of discrimination against women in the sexual sphere, because punishment is an act of total asymmetry of power between two parties. The suffering individuals cannot defend themselves, hide or return the blow; in fact, they may be completely defenceless. For this reason, torment is an example of the total objectification of the individual.

\subsection{Intimate Body Parts}

Before embarking on the analysis proper, it is vital to highlight that human sexual organs ${ }^{9}$ constitute a very controversial topic and are habitually ignored and avoided in general discourse (see Duda, 2014). The investigation presented in the previous section shows that sex is often viewed as a violent interaction, in which a man is characterised as an attacker, and his penis might be viewed as a weapon ${ }^{10}$. In this regard, Morton (2003) claims that a great number of terms denoting the penis are taken from the battlefield. $\mathrm{He}$

\footnotetext{
${ }^{9} \mathrm{Up}$ to the present time there have also appeared a number of new terms denoting vagina, nevertheless, almost all of them contain a figurative meaning, and people still avoid talking about it directly. Even gynaecological clinical vocabulary that is supposed to be very specific, has its roots in metaphors. The very word vagina is a Latin term and it means 'sheath' or 'scabbard', a kind of holster for storing a sword (Morton, 2003). Moreover, female breasts have not escaped comparisons to war terminology either, and they are frequently depicted as weapons of mass destruction. Morton (2003) enumerates the following expressions: atom bombs, flesh bombs, torpedos, cannons, howitzers, scuds, warheads and bazookas.

${ }^{10}$ What is even more remarkable, while penis is very often presented as a weapon, usually a sword, the woman's intimate part adopts the name of scabbard or sheath. Not infrequently, however, penis can also be described by the extensions of words that simply represent items that are phallic in shape.
} 
writes: "the word weapon itself was used to denote the penis in Middle English, as it had been in Old English, dating back to the eleventh century" (Morton 2003). The term is still often used nowadays and there seems to be a close connection between sex and war, where masculinity is seen as a kind of dominance, femininity as passivity, and sexual intercourse as a conquest.

The metaphorical view of the penis as a weapon that is used during war becomes crucial when assessing the relationship between sex and violence. Awareness of the semantics of sexual intercourse and violence among men becomes pivotal, simply because men must constantly define themselves through their masculinity. In order to understand the metaphorical correspondences between the two domains, let us analyse certain examples:

My favorite position. I tried to hold my phone steady as her hand guided my shotgun inside her. "Penthouse" 3/2017.

She grabbed the back of the chair, which was flimsy, and braced it against the wall, which was flimsy. I trusted this girl could withstand ten days of my pent-up logjam. With her feet spread and her ass pointing at me, her bush riding beneath like a hair beacon, I guided my Scud missile in, grabbing each hip once I was there. "Penthouse" 12/2016.

There's something menacing about a guy wielding his penis like a weapon. "Playboy" 10/2016.

I was on the brink of shooting my load. "Penthouse" 12/2017.

No more than three minutes passed before I was shooting into her mouth. "Penthouse" 2/2016.

I moaned as he muscled his oversized gun into my tight little hole. "Penthouse" 6/2016.

At first glance, it can be inferred that the penis is characterised as a weapon (shotgun, Scud missile), whereas ejaculation is characterised as the act of shooting with the weapon (shoot the load). Hence, the hostile and violent manner of war is attributed to the manner of the sexual act. By shooting the loaded weapon, the attacker attempts to kill the victim, and so - the woman - his sexual partner. Such a perception highlights the negative characteristic of violence. The male genital organ can be used as a weapon, with the intention of humiliating and subordinating the victims, or worse, with the intention of objectifying them.

\subsection{Depiction of the Kissing Act}

Other less dangerous and vicious forms of combat include kissing. Because a kiss is a form of very intimate contact, it evokes strong emotions. That is why people most often prefer to kiss only very close friends and those with whom they are intimately acquainted. In a relationship, the type and manner of kissing also carries cultural meanings not directly related to sexuality. Depending on the context, the degree of knowledge we possess, or the relationship between people who exchange a kiss, it can be a sign of respect, friendship or a way of greeting or saying goodbye. Yet, kissing can also constitute an act that is a passionate prelude to intercourse and emphasise the intensity of sexual desire (see Morton, 
2003). The existence of the KISSING IS WRESTLING metaphor can be confirmed by the following excerpt:

Our lips met and our tongues wrestled as she rocked on my stiff pole. "Penthouse" $12 / 2017$.

The connection between the domain of sex and that of war is evident here in the word wrestled. In simple terms, wrestling is a combat sport, involving the physical struggle of two competitors - the fight takes place by using grips and throws. Although not everyone is aware of this, anger and combat have a lot in common with eroticism. Aggressive kisses might make some people very excited, nonetheless it should not be assumed that such a perception indicates only a positive side of human sexual desire.

On balance, the WAR and PUNISHMENT metaphors are popular media images. In many cases, the overall view of sex seems to be one of hostility, violence and dominance where the two domains very often function as devices of masculinisation, since war is still typically perceived as a male activity ${ }^{11}$. Moreover, such metaphors influence the way of thinking about sex and the way of making love itself. Strengthening and highlighting of the portrayal of male's sexual dominance may encourage readers of these magazines to become more violent. It is vital to bear in mind that metaphors are not culturally neutral, and they possess the power to shape people's attitudes towards sexuality, not always favourably. They also emphasise different facets of sex, and - at the same time - they background other aspects, like tenderness, caring for the partner and other positive emotions occurring during intercourse. Therefore, the fact that metaphors might be used as a vehicle to transmit stereotyped images is frequently exploited by the media.

\section{LANGUAGE, GENDER AND IDEOLOGY}

The contemporary media influence the formation and continuation of public opinion and so, for this reason, it is hardly surprising that language and gender researchers have dedicated a lot of attention to different forms of media, including newspapers and magazines (Litosseliti, Sunderland, 2002; del-Teso-Craviotto, 2006; Williams, 2012; McNair, 2013). To a large extent, the media can be treated as a reflection of reality, yet, they play a key role in the process of its construction. They not only spread stereotypes, but being an integral part of today's society, they have immense power to guide the perceptions and influence the opinions of the mass audience. It is also evident that the portrayal of women and men is very often stereotypical, and the presented sex-related metaphorical expressions further reinforce gender standards and norms deeply rooted in consciousness and in language. The image of both sexes concerning sex places strong pressure on readers to conform with the established, traditional concepts of gender roles and behaviour.

It can be suggested then that, on the one hand, language reflects ideologies, and on the other hand, it creates them. Such a view is shared by many researchers. Wodak (1997), for instance, claims: "Discourse is socially constituted, as well as socially conditioned". This indicates an important area of interest in language and gender research. Most of the western languages are largely androcentric, and, therefore, they build largely androcentric worlds that are questioned by feminism. In some significant respects, sexual language is an important tool for insulting women. What is more, sex is one of the obvious sources of

\footnotetext{
${ }^{11}$ See e.g. Duda (2014).
} 
swear words and insults, and they are frequently used along gender lines (see, among others, Ljung, 2007; Bolinger, 2014). By means of defining the sexual nature of women, it constitutes an obvious and widespread way of humiliating them. From the plethora of arguments, also pornography ${ }^{12}$ might be considered as another form of the exercise of power, where females linger in a precarious position. Without an uncompromising and radical upheaval, they may only choose a place in the culturally developed scheme in which they are treated as objects that meet male biological needs.

By conceptualising one thing in terms of another, metaphor has the extraordinary power of masking intentions, and, of course, it is especially convenient when the hidden message is negative, discriminatory and sexist. With the use of this type of sexist metaphors in everyday language and their ubiquity in the language of the media, modern media consumers are often unable to recognise the original intentions and assumptions of the metaphorical expressions applied. Hence, these metaphors are considered to be truth and are accepted at face value.

\section{CONCLUSIONS}

This article sheds some light on the phenomenon of conceptual metaphor and on the significance of sex-related figurative expressions from the point of view of gender inequality. It can be stated now that conceptual metaphors constitute a vital part of the world that people live in and they play a tremendous role in their lives, especially in understanding reality and stereotypical reasoning. Bearing this in mind, the media (like American magazines discussed here) with, to a large extent, its ideological language is largely responsible for creating social and cultural reality. Moreover, since metaphors arise spontaneously and automatically, often without human awareness, it seems that people have little or no choice in whether to think metaphorically or not. As the mechanism of metaphor is mostly unconscious, once they become assimilated, they remain part of people's active and passive lexicon.

First of all, the SEX IS WAR metaphor is a cognitive association that transfers various attributes from the source domain of war to the target domain of sex. To be more precise, it offers various sets of ontological correspondences as a result of using knowledge of war to talk about the taboo topic of sex: for example, a lover is an enemy; seduction of a sexual partner is to defeat an enemy; penis is a weapon etc. The conceptual basis of war metaphors refers to the general view of sex in terms of dominance, punishment, hostility and violence; therefore, many metaphorical substitutes that are subject to this cognitive equation tend to acquire dysphemistic overtones.

Proceeding further, metaphor is recognised as a tool responsible for shaping human thought and perception and, consequently, the social and cultural landscape. From the biological perspective, sex might be treated as a means of conceiving children, hence as a way of extension of the existence of a family and passing on genetic material from parents to offspring. Nevertheless, the analysis undertaken shows that the concept of sex goes much deeper than a simple act serving the mechanical perpetuation of the species. As has been proven, it touches on the cultural and social factors that govern the use of figurative

12 Pornographic language is possibly aggressive because it can destroy women's intimacy and self-respect. Pornography (indeed more than eroticism) overcomes and destroys all courtesy expectations - while erotic language can be used to stimulate positive reactions from readers or speakers, pornography is a deliberate attack on the dignity of others (mainly women). 
expressions. One cannot be partially and selectively at war - the inclusion of such a description of reality in a male-female relationship incorporates certain beliefs that begin to strongly shape this relationship, which, in the long run, may have a negative impact.

Similarly, the domains of WAR and PUNISHMENT clearly suggest the superiority of man. For many men, sex serves as a basis of self-worth in the modern world. By various sexual activities, they show their skills in seduction and prove their attractiveness and desirability. The metaphor of war promotes specific behaviours - competitive rather than conciliatory, where emphasis is put on the effect and not the way it is achieved; in other words, the achievement of the goal is the most crucial element, not the interests of the individuals. The very notion of interests in the war metaphor turns into abutments, bases and all other goals that are gained (by force), and not agreed or negotiated. Thus, the metaphor of war includes victims, thrown from front to front like pawns on a strategic map. What is perhaps even more important, it imposes win-lose optics. Compromise is always treated as an unfulfilled desire, and winning becomes the only goal. The metaphor of war even excludes the search for agreement and satisfaction of both parties.

Having said that, metaphors constitute a perfect way to refer to delicate issues, especially in the area of lovemaking, yet one should not underestimate their impact on our reasoning, since they are natural phenomena. Every conceptual metaphor is an inseparable part of human thought, just as linguistic metaphors are part of human natural speech. Additionally, metaphor may be considered a dynamic device that is changing, developing, extending, all depending on the person and situation. When people talk to each other, when they take part in various discussions and public conversations, when they explain themselves to others, they make abundant use of conceptual metaphors. Their choice of metaphor not only reveals the intended conceptualisations, but most of all it conveys their attitudes, emotions and values. A discussion on the ways of talking about lovemaking constitutes an important element of every modern, homogenous culture, especially when we consider the phenomenon of gender inequality. Hence, this study adds another piece to the puzzle in the field of Cognitive Linguistics and gender studies.

\section{REFERENCES}

Baider, F. H., Gesuato, S. (2003). Masculinist Metaphors, Feminist Research [Access: 5.07.2020]. Access on the internet: http://www.metaphorik.de/sites/www.metaphorik.de/ files/journal-pdf/05_2003_baidergesuato.pdf

Bolinger, D. (2014). Language - The Loaded Weapon: The Use and Abuse of Language Today. London: Routledge.

Cameron, D., Kulick, D. (2003). Language and Sexuality. Cambridge: Cambridge University Press.

Cheney, V. T. (2004). The Sex Offenses and Their Treatments: The Problem - The Solution The Commentary. Bloomington, Indiana: AuthorHouse.

del-Teso-Craviotto, M. (2006). Words that Matter: Lexical Choice and Gender ideologies in women's magazines. "Journal of Pragmatics" 38.

Dobrovol'skij, D., Piirainen, E. (2005). Figurative Language: Cross-cultural and Cross-linguistic Perspectives. Amsterdam: Elsevier.

Duda, B. (2008). Downstairs, Upstairs and Other You-Know-Whats. On Human Conceptualization of Taboo. "Studia Anglica Resoviensia" 8. 
- (2014). The Synonyms of Fallen Woman in the History of the English Language. Frankfurt am Main: Peter Lang Edition.

Gibbs, R. W. (1994). The Poetics of Mind: Figurative Thought, Language and Understanding. Cambridge: Cambridge University Press.

Goatly, A. (2007). Washing the Brain: Metaphor and Hidden Ideology. Amsterdam: John Benjamins Publishing.

Lakoff, G., Johnson, M. (1980). Metaphors We Live By. Chicago: The University of Chicago Press.

Lakoff, G. (1987). Woman, Fire, and Dangerous Things: What Categories Reveal about the Mind. Chicago: The University of Chicago Press.

Litosseliti, L., Sunderland, J., eds. (2002). Gender Identity and Discourse Analysis. Amsterdam: John Benjamins Publishing Company.

Ljung, M. (2007). Swearwords. Denmark: Nörhaven Paperback.

Kövecses, Z. (1986). Metaphors of Anger, Pride and Love. Benjamins: Philadelphia.

- (2005). Metaphor in Culture: Universality and Variation. Cambridge: Cambridge University Press.

- (2008). Metaphor and Emotion [In:] Gibbs, R. W., The Cambridge Handbook of Metaphor and Thought. Cambridge: Cambridge University Press.

— (2010). Metaphor: A Practical Introduction. Second Edition. Oxford: Oxford University Press.

- (2015). Where Metaphors Come From: Reconsidering Context in Metaphor. Oxford: Oxford University Press.

- (2020). Extended Conceptual Metaphor Theory. Cambridge: Cambridge University Press.

MacKinnon, C. (1982). Feminism, Marxism, Method, and the State: An Agenda for Theory. "Signs", Vol. 7, No. 3, Feminist Theory (Spring, 1982).

Maslow, A. H. (1943). A Theory of Human Motivation. "Psychological Review" No. 50 (4).

McNair, B. (2013). Porno? Chic! How Pornography Changed the World and Made it a Better Place. New York: Routledge.

Morton, M. (2003). The Lover's Tongue: A Merry Romp Through the Language of Love and Sex. Toronto: Insomniac Press.

Oxford English Dictionary (OED). Access on the internet: https://www.oed.com/.

Williams, T. R. (2012). Empowered Femininity: The Textual Construction of Femininity in Women's Fitness Magazines. Newcastle upon Tyne: Cambridge Scholars Publishing.

Wodak, R., ed. (1997). Gender and Discourse. London: SAGE Publications.

DOI: 10.7862/rz.2021.hss.04

The text was submitted to the editorial office: July 2020.

The text was accepted for publication: March 2021. 
